\title{
Numerical Investigation on Flood Water Sloshing Influence on Intact and Damaged Stability of Ship
}

\author{
POONAM MOHAN, A. P. SHASHIKALA \\ Department of Civil Engineering, National Institute of Technology Calicut \\ INDIA
}

\begin{abstract}
Sloshing affects the intact and damage stability of the ship, which causes variation in dynamic metacentric height (GM) under critical load conditions. The transient flooding soon after the ship damage is analyzed, with floodwater accumulation in large space and causing the ship to suffer huge heel angles. The ship motion and stability changes when sloshing becomes high in partially flooded compartments. Most of the previous researches focus on the motion response of ship alone, hence the variation of stability due to sloshing is to be more critically studied. In the present study, three critical damage locations are identified and flooding through these locations are analyzed using the volume of fluids method. The method focus on finding damage ship motion response, flood water dynamics, and coupled dynamics of both. This is studied using the numerical method FLOW3D. Motion and stability behaviour will be different for different damage locations; hence portside, starboard-side, and aft-end bottom damage cases are considered. The effect of compartment shape and damage location on motion response and stability of the damaged ship is highlighted.
\end{abstract}

Key-words: Sloshing; Damage Stability; Compartmental Flooding; Metacentric height spectrum

Received: April 22, 2021. Revised: October 16, 2021. Accepted: November 6, 2021. Published: December 19, 2021.

\section{Introduction}

Damage stability is a critical phenomenon and highly nonlinear,where flood water accumulates on compartments and increases ship metacentric height. Water contained in a compartment behaves similar to a partially filled sloshing tank, which can influence the stability of ship by varying metacentric height, GM. The drainage to lower decks actually increases GM, because of lowering KG. The metacentric height decreases because of the free-surface effect When the internal space of damage location is large, capsize probability is higher due to larger free surface area and shifting of vertical and horizontal center of gravity. A significant amount of attention is to be given to this phenomenon even though it is difficult to analyze. Many researchers have tried the numerical prediction of damaged ship motion. Coupled slosh and damaged condition of ships are considered as a multibody dynamic system. The damage stability of the ship can be determined using probabilistic and deterministic methods. Ro-Ro ship use probabilistic method to assess critical damage locations based on loading conditions. Bulkheads preserve buoyancy of ship, divides ship into zones, and extends from hull bottom to top-deck above the waterline, hence it could stay afloat for a longer time. The impact force of floodwater creates structural damage to the ship. The stability regulations Safety of Life at Sea (SOLAS) 1990 and International Marititme Organization (IMO) are evolving continuously, and many scientists work to fill gaps or flaws in stability performance of ship and to improve the predictability of behavior of ship corresponding to each critical situation $[9,23]$. Roll onRoll off ships with low GM have greater chances of stability losses even without damage when compared to all other types of ships. Experimental analysis is hectic, time-consuming, and needs huge money investment, moreover results greatly depend on experimental facility and accuracy of instruments. Hence intensive numerical studies.

The value of $K G$ varies with free surface effect due to flood water ingress. Often, worst damage cases are included in the stability booklet of a ship chartered for the sail. Also, most of the stability measuring instruments on-board consider maximum damage extends to measure the intermediate stage of flooding. 


\begin{tabular}{|c|c|c|c|}
\hline \multicolumn{4}{|c|}{ NOMENCLATURE } \\
\hline$\overline{\mathrm{H}}$ & Wave height (m) & $\nabla$ & Displaced volume \\
\hline $\mathrm{H}_{0}$ & Sea level (m) & $\Delta$ & Displacement \\
\hline $\mathrm{g}$ & Acceleration due to gravity, $\left(\mathrm{m} / \mathrm{s}^{2}\right)$ & $\lambda$ & Scale factor \\
\hline GM & Transverse Metacentric height, (m) & $\rho$ & Density of water \\
\hline$\ddot{X}$ & Acceleration of $\operatorname{ship}\left(\mathrm{m} / \mathrm{s}^{2}\right)$ & $k$ & Wavenumber \\
\hline$\dot{\boldsymbol{X}}$ & The velocity of $\operatorname{ship}(\mathrm{m} / \mathrm{s})$ & $\mathrm{M}_{\mathrm{kj}}$ & Mass moment of inertia of ship \\
\hline$f_{\text {ext }}$ & External forces $(\mathrm{N})$ & $\mathrm{m}_{\mathrm{kj}}$ & Fluid mass matrix \\
\hline $\mathrm{B}$ & Breadth of ship (m) & $\bar{x}_{i}$ & Acceleration mode $j$ \\
\hline BOA & Overall beam & $\tilde{x}$ & Velocity mode $j$ \\
\hline $\mathrm{B}_{\mathrm{WL}}$ & Beam at waterline & $\mathrm{B}_{\mathrm{kj}}$ & Damping mass \\
\hline $\mathrm{L}_{\mathrm{pp}}$ & Length $\mathrm{b} / \mathrm{w}$ perpendicular of ship $(\mathrm{m})$ & $\mathrm{C}_{\mathrm{kj}}$ & Instantaneous stiffness \\
\hline LwL & Length at waterline & $\mathrm{R}_{\mathrm{kj}}$ & Matrix of Retardation function \\
\hline Loa & Overall length of ship (m) & $i$ & Time delay \\
\hline M & Ship mass (kg) & $\mathrm{x}_{\mathrm{i}}$ & Motion mode $\mathrm{j}$ \\
\hline $\mathbf{m}_{\mathrm{ext}}$ & Added external mass (Nm) & A & Wave amplitude (m) \\
\hline$Q(t)$ & Flow at time $\mathrm{t}\left(\mathrm{m}^{3} / \mathrm{s}\right)$ & LCG & Longitudinal position of CG \\
\hline$\theta$ & Angular acceleration of ship $\left(\mathrm{rad} / \mathrm{s}^{2}\right)$ & KG & Height from keel to CG \\
\hline$\dot{\theta}$ & Angular Velocity of ship (rad/s) & KM & Height from keel to metacenter \\
\hline$\theta$ & Angle of roll (rad) & $\omega$ & Wave Frequency \\
\hline$\Phi$ & Angle of pitch (rad) & $\omega_{\mathrm{N}}$ & Roll natural frequency \\
\hline$\lambda_{w}$ & Wavelength (m) & TANI & PROPERTIES \\
\hline $\mathrm{T}$ & $\operatorname{Draft}(\mathrm{m})$ & 1 & Rectangular tank length (m) \\
\hline $\mathrm{T}_{\mathrm{W}}$ & Wave period of sloshing (s) & $\mathrm{b}$ & Rectangular tank Breadth (m) \\
\hline $\mathrm{COG}$ & Centre of gravity & $\mathrm{h}$ & Height of water inside tanks (m) \\
\hline $\mathrm{t}$ & Time series & $\omega_{\mathrm{n}}$ & Sloshing frequency $(\mathrm{rad} / \mathrm{s})$ \\
\hline $\mathrm{Tp}$ & Roll resonant period & $\mathrm{T}_{\mathrm{n}}$ & Natural period of sloshing (s) \\
\hline$x_{k}$ & Displacement mode $k$ & $\mathrm{H}_{\mathrm{t}}$ & Flooded water height in a compartment \\
\hline$\eta$ & Wave elevation & & \\
\hline
\end{tabular}

The compartment subdivision of ship is considered in probabilistic damage stability analysis to find the critical damage locations. A simulation using VOF method for coupling sloshing on damaged ship with water ingress and egress through damage location is not been performed in previous studies. A proper model of floodwater ingress and its internal dynamic sloshing nature inside the damaged compartment of ship is developed in the present study using a numerical method.

The Computational Fluid Dynamic (CFD) technique, which is based on the volume of fluids method (VOF) is adopted at zero forward speed in regular waves.

\subsection{Review of Literature}

Damaged ship behaves differently at the transient, intermediate and final stages. Transient condition occurs suddenly on impact or collision of a ship and induces permanent initial heel, which makes ship unstable and cannot return to its initial stable state. At the intermediate stage, water continuously undergoes inflow and outflow through the compartment due to the action of waves. In this stage, sloshing causes motion and stability changes, and a continuous non-linearity exists.

In the case of Ro-Ro ship, there is no internal bulkhead to resist the flow of water from one compartment to another. The work done by Bird and Browne [2], highlighted that capsizing differs with sea state parameters like wave height. Ro-Ro ship was experimented for different sea states, loading conditions, and how it induces roll motion. Kambisseri and Ikeda [12] studied the effect of water ingress through damaged locations and how it loses stability based on size of damage opening. Partially flooded compartment was considered in the work of De Kat [4] on a tanker model in beam sea using a time-domain model to calculate large amplitude motion response, neglecting free surface effect. 
Palazzi and de Kat [19] did a time-domain analysis and model testing to study flooding behavior using a damaged frigate ship for both regular and irregular waves. Santos and Guedes Soares [25] used shallow water theory and performed time-domain simulation on passenger ships using regular waves in beam seas conditions. Ross et al. [24] compartmentalized the Ro-Ro ship model with six and nine compartments, which gave better results than other similar research works. Korkut et al. [14] performed motion analysis on an intact and damaged ship to understand sea keeping behavior for large, medium and small wave heights and a range of wave period for the head, beam and stern quartering seas and have reported that the response is a function of wave direction and frequency. Santos and Guedes Soares [26] predicted the behavior of damaged ships with progressive flooding. They observed that accumulated water increase the volume, which causes ship to capsize and reduces survivability duration of ship. Damage size, compartmentalization, and geometry of damage influence transient flooding. Intermediate flooding was very severe, inducing free surface instability and finally ship collapses within a short duration. The Meshless or Moving Particle SemiImplicit (MPS) method was used to track moving particles to study the free surface effect impact by Nishimoto et al. [18] Coupling of free surface effect was ignored, and forces and moments which cause changes to hull stability and damping to hull motion were studied. Water progressing through damaged location in a ship was studied using a time-domain simulation on Beam Sea by Vassalos [27,28]. Length and breadth of damage in any location throughout the ship are related to survivability of ship. KhaddajMallat et al. [13] investigated transient flooding and free surface effect in internal compartments and tried to find a model that clearly describes the intermediate flooding stage. The flow of water around hull by including damaged compartments was analyzed using the MPS method by Hashimoto et al. [7]. Floodwater sloshing induces roll moment along with wave-induced moment acting on the ship. Huang et al. [8] investigated the floodwater effect on ship roll response subjected to regular beam waves. Flood water effect can be predicted by extreme motion of inertia dominant ship with free surface effect. Mironiuk [17] studied flooding time by designing a quasi-static approach. Lorkowsk [15] considered intermediate stages of flooding for multiple damage scenarios in a short duration. Ruponen et al. [16] studied the impact of flooding water on noncompartmentalized parts of ship and proved that momentum at that region has to be accounted for, and viscous damping was assessed from transient flooding test. Boulougouris [3] compared probabilistic and deterministic methods in terms of ship survivability. Acanfora et al. [1] studied ship damage effects on the free surface, and fluidstructure interaction was more. They studied three different damage scenarios for same compartment in beam waves. Manderbacka and Ruponen [16] studied abrupt flooding while varying damage size.

In the present study, fully coupled simulation of a flooded compartment of a ship in waves is done. This work studies the effect of damage location on ship response and stability. When wave acts on a damaged ship, water flows in and out through the damage opening. Ship displaces higher volume due to this, and ship is set to different drafts. On reaching a steady-state, the corresponding draft under damaged condition, the wave induces sloshing on floodwater inside damaged compartment. Single compartment damages are usually not given much importance. Hence, in the present study side and aft end damage along with adjacent compartments are considered. Mostly one side damage is given importance, and ship is assumed symmetric, while in this study, compartments on both sides are considered to be flooded.

\subsection{Theoretical Background}

The time domain analysis is performed using CFD software FLOW3D using volume of fluids (VOF) method. The study can be classified into three section, the ship stability after damage, the flood water dynamics and the ingress and egressof water through damage section.

\section{- Ship Motion and Stability}

The ship co-ordinate axis in stable condition is $(\mathrm{X}, \mathrm{Y}, \mathrm{Z})$, and that of the inclined state is $\left(\mathrm{X}^{\prime}, \mathrm{Y}, \mathrm{Z}^{\prime} \mathrm{Z}^{\prime}\right)$ as shown in Fig 1a. The flooded compartment, which is open to the sea, will have a variation of water level inside the compartment according to changes in ship motion. The ship after damage uses the researve buoyancy to stay afloat as shown in Fig $1 \mathrm{~b}$ and it tilts to the side where the flood water accumulates and KB increases, while BM decreases. Finally the ship gaines negative GM and collapses. Most damage 
cases include two-compartment damages. The minimum possible vertical extent of damage is $(d s+12.5) \mathrm{m}$ as shown in Fig 1(b). Operational trim is $\pm 0.5 \%$ of length of ship, $L$. Following IMO specification[10], damages in the present study are extended beyond centerline. For side damage, a longitudinal extent is $\mathrm{L}^{2 / 3} / 3$ or $14.5 \mathrm{~m}$ whichever is less, and transverse extend is $\mathrm{B} / 5$ or $11.5 \mathrm{~m}$ whichever is less. For bottom damage, transverse extend is $\mathrm{B} / 6$ or $10 \mathrm{~m}$ if the damage is located $0.3 \mathrm{~L}$ from forward or aft perpendicular and vertical extent are $\mathrm{B} / 15$ or $6 \mathrm{~m}$, longitudinally extend the same as in the case of side damage.

Response amplitude Operator (RAO) is calculated by performing the Fourier series analysis of heave, pitch, and roll time-series response. Numerical analysis retrieves time history data of motion response of heave, roll, pitch, and also stability parameters like GM variation corresponding to degrees of freedom. Hydrodynamic frequency domain characteristics are converted to the time domain using Impulse Response Factor (IRF), while time-domain results can be changed to results with respect to frequency using Fast Fourier Transform (FFT) by performing Spectral Analysis.

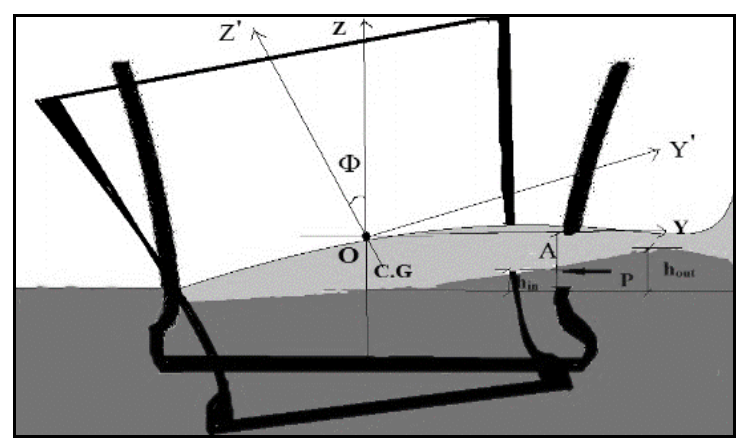

(a)

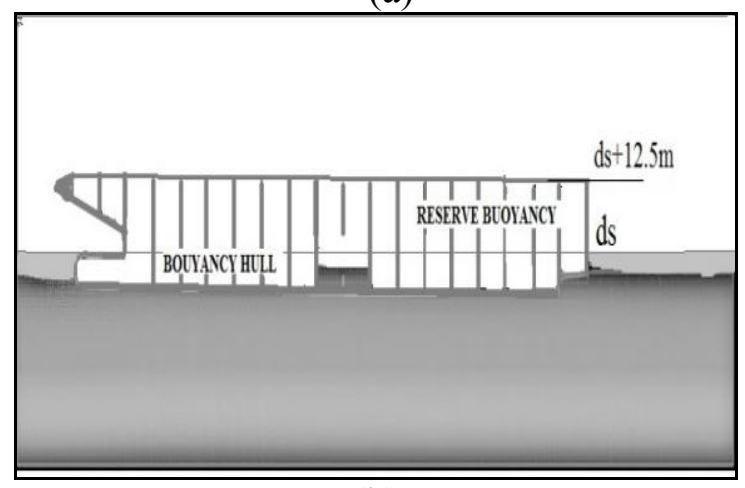

(b)

Fig. 1: (a) Lost buoyancy and Reserve buoyancy (b) Co-ordinate system
A flooding condition can be elaborately defined by vassalo [27,28] as shown in Eq 1. The excitation force is a function of wave $F_{K}^{\text {Wave }}(t)$, wind $F_{K}^{\text {Wind }}(t)$, current $F_{K}^{\text {Current }}(t), \quad \operatorname{drift} F_{K}^{\text {Drift }}(t), \quad$ gravity $F_{K}^{\text {Gravity }}(t)$ and flooding $F_{K}^{\text {Flood }}(t)$. At time $t$, the ship mass $M(t)$, flood water mass $M_{w}(t)$, and added mass $m$ together contribute to motion behaviour. The Flood-water velocity at time $t$ is $\dot{M}_{W}(t)_{k j}$. In the present study, the ship model in the flooded scenario is defined by Eq. 2 .

$$
\begin{aligned}
& \left.\sum_{j=1}^{6}\left[M(t)_{b j}+M_{W}(t)_{k j}+m_{k j}\right] \ddot{x}_{j}+\left[\dot{M}_{W}(t)_{b j}+B_{k j}\right] \dot{x}_{j}+C_{k j} x_{k}+\right) \\
& +\int_{-\infty}^{t}\left[R_{f}(t-\tau) \dot{x}_{j}(t) d \tau\right]=F_{K}^{W \pi r \varepsilon}(t)+F_{K}^{W i n g}(t)+
\end{aligned}
$$

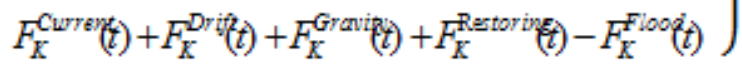

Motion equation of damaged ship derived from linear and angular momentum may be represented as:

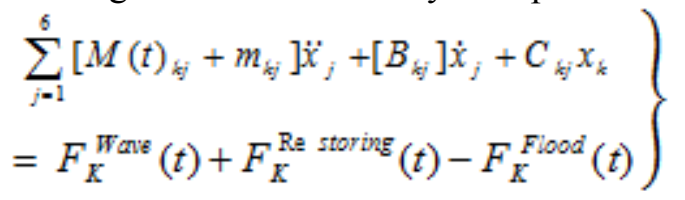

Time-domain based coupled motion equation can be represented as:

$$
\left.\begin{array}{c}
\sum_{j=1}^{6}\left[M_{k j}+m_{k j}\right] \ddot{x}_{j}+B_{k j} \dot{x}_{j}+C_{k j} x_{k}+ \\
\int_{-\infty}^{t}\left[R_{k j}(t-\tau) \dot{x}_{j}(t) d \tau\right] \\
F_{K}^{\text {Ware }}(t)+F_{K}^{\text {Restoring }}(t)-F_{K}^{\text {Flood }}(t) F_{K}^{\text {Slosh }}(t)
\end{array}\right\}
$$

The response obtained in FLOW3D is coupled response of ship with floodwater, hence the primary peak response in RAO will be at the resonant frequency of a ship, while small peaks will give the frequency of sloshing of floodwater inside ship. Metacentric height spectrum or GM-spectrum can be used to define stability variations of ship both in intact and damaged condition (Dunwoody, 1989). Metacentric Height $G M$ of a ship is the sum of $G M$ in still water and fluctuating $\mathrm{gm}$, which is a function of wave elevation and pressure. Metacentric height GM contains heave, roll pitch values of higher power due to wave elevation, and floodwater pressure. However, generally, it can be represented as: 


$$
g m=\frac{1}{\Delta} \int_{L}\left(f_{1} \eta+f_{2} \ddot{\eta}\right) d x
$$

Where $f_{1}, f_{2}$ are constants. Assuming wave elevation $\eta$ and wave acceleration as:

$$
\begin{gathered}
\eta(X, t)=\int_{-\infty}^{\infty} e^{i(k x-\omega t)} d A(\omega) \\
\ddot{\eta}(X, t)=\int_{-\infty}^{\infty}-\omega^{2} e^{i(k x-\omega t)} d A(\omega)
\end{gathered}
$$

By substituting Eq. 5, 6 in Eq.4, we get $g m$ in terms of differential wave amplitude $D(\omega)$ as a function of frequency $\omega$. Auto-correlation function $R_{a c}$ of fluctuating $g m$ at time $t$ in terms of spectrum $S(\omega)$ is obtained. $S(\omega)$ is a function of $\omega$ and $\omega_{e}$. For deep sea condition, dispersion relation can be applied and the three frequencies $\omega_{1}, \omega_{2}$, and $\omega_{3}$ can be calculated. Frequency $\omega_{1}$ is a peak frequency of ship when encountered with wave, while $\omega_{2}, \omega_{3}$ are factors of floodwater sloshing or if ship has forward speed, as shown in Eq 7 given by Dunwoody (1989). In the present study, ship speed $U$ is zero, hence multiple peaks in the GM spectrum shows effect of sloshing (Eq 7).

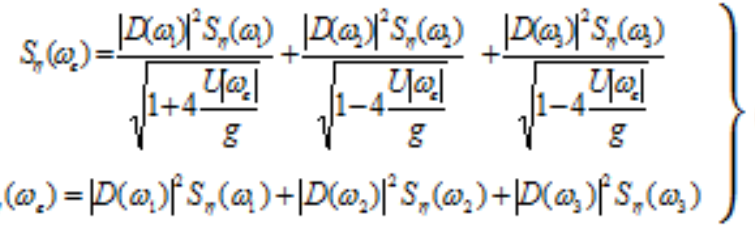

Eq 7 gives the Power Spectral Density (PSD) of system which is plotted with respect to frequency. It can capture the probability with which function is repeated during a period of time. The influence of sloshing vibration of floodwater on damage compartment is found. For this single point response spectrum (SPRS) is plotted corresponding to the $C G$ of ship. The region inside GM displacement PSD is square of standard deviation of response. Response spectrum analysis is done to get overall ship motion response, while the Metacentric height (GM) spectrum shows variation of ship stability due to liquid sloshing. Metacentric height variation is a function of roll and pitch response amplitudes. Metacentric height spectrum displays restoring capacity of ship to its stable state when encountered with different sea states.

- Flood water slosh dynamics
When free surface area is more,the flood water sloshing dynamics occur and can also affect the reserve buoyancy as shown in Fig 1(a). The cross flooding of ship is allowedTime-domain analysis couples ship response with flood water dynamics inside the tank using Navier- Stokes equation (Eq 8,9 ). For considering flood water, the equation of motion of a damaged ship subjected to wave is represented by Pantazopoulos [20] as shown below:

$$
\begin{gathered}
\frac{\partial v}{\partial y}+\frac{\partial w}{\partial z}=0 \\
\frac{\partial u}{\partial t}+u \frac{\partial u}{\partial x}+v \frac{\partial u}{\partial y}=-a_{z} \frac{\partial \lambda}{\partial x}+\mathrm{F}_{1}(\mathrm{x}) \\
\frac{\partial v}{\partial t}+u \frac{\partial v}{\partial x}+v \frac{\partial v}{\partial y}=-a_{z} \frac{\partial \lambda}{\partial y}+\mathrm{F}_{2}(\mathrm{x}) \\
\frac{\partial \lambda}{\partial t}+u \frac{\partial \lambda}{\partial x}+v \frac{\partial \lambda}{\partial y}+\lambda \frac{\partial u}{\partial x}+\lambda \frac{\partial v}{\partial y}=0
\end{gathered}
$$

Here, $F_{1}(x), F_{2}(y), a_{z}$ are force acted upon by the floodwater at damage opening. In large ships, floodwater is in phase with ship roll, and its free surface will be parallel to the water plane. However, when the floodwater is of large volume, resonant condition can occur due to sloshing at peak roll frequency. Water ingress depends on the relative position of damage location and wave elevation on either side of the opening. Bernoulli's equation in Eq.10 can be adopted for a particular head and velocity of floodwater at eigther side of damaged location $A$. The pressure $p$, density $\rho$, flow velocity $u$, and height from the reference level is used to calculate flow rate $Q$ as given by Eq. 11 .

$$
\begin{gathered}
\int_{A}^{B} \frac{d p}{\rho}+\frac{1}{2}\left(u_{b}^{2}-u_{a}^{2}\right)+g\left(h_{b}-h_{a}\right)=0 \\
\left.Q=C_{D} \cdot A \sqrt{2 g\left(h_{\text {in }}\right.}-h_{\text {out }}\right)
\end{gathered}
$$

The liquid weight keeps on adding to ship. Flood water dynamics inside compartment is based on continuity equation:

$$
\begin{gathered}
\frac{\partial \rho}{\partial t}+\nabla \cdot(\rho u)=0 \\
\frac{\partial \rho v}{\partial t}+\nabla \cdot(\rho v \cdot v)=-\nabla p+\nabla \tau+\rho g+F
\end{gathered}
$$

Force and moment acting on ship hull due to external wave and internal flood water may be represented as shown below:

$$
\vec{f}=-\iint_{S} p n d s
$$




$$
\vec{m}=-\iint_{S} p \vec{r} \times \vec{n} d s
$$

Roll, heave, and pitch are given by:

$$
\left\{\begin{array}{l}
\mathrm{m}_{\mathrm{r}}=\overrightarrow{\mathrm{m}} \cdot \mathrm{x} \\
\overrightarrow{\mathrm{m}}_{\mathrm{p}}=\overrightarrow{\mathrm{f}} \cdot \overrightarrow{\mathrm{Y}} \\
\mathrm{m}_{\overrightarrow{\mathrm{h}}}=\overrightarrow{\mathrm{m}} \cdot \mathrm{Z}
\end{array}\right\}
$$

\subsection{Ship Details}

The present study is to find stability variation of intact ship with sloshing tanks and how sloshing inside damage compartment contributes to stability loss of ship (Fig 2).

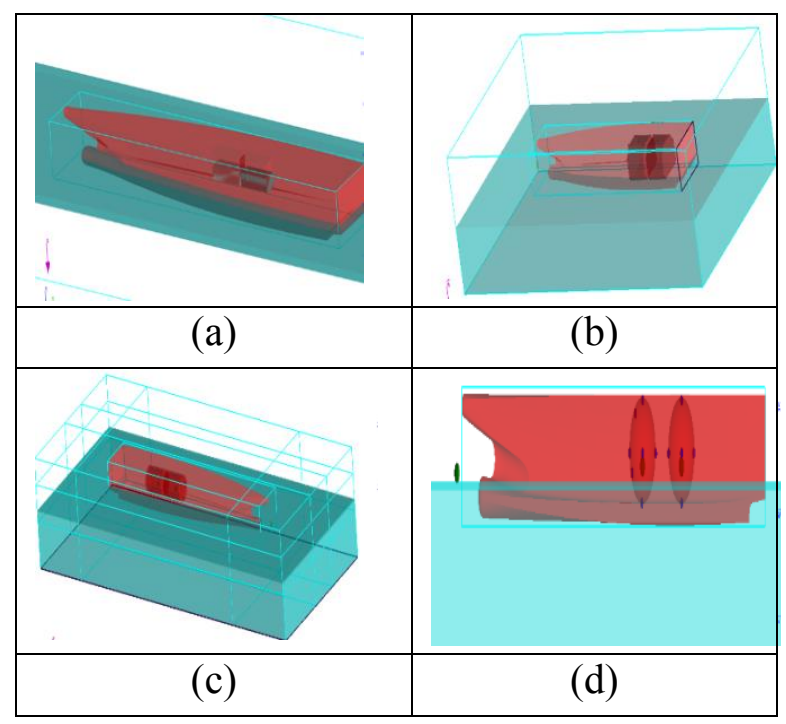

Fig. 2: Ship with sloshing tank (a) Prismatic (b) Rectangular (c) Cylindrical (d) Spherical

The prototype is considered for numerical analysis as scale effect can affect ship damage stability results. The fluid is incompressible and inviscid, and the ship is considered to be impermeable. To reduce time consumed for simulation, the ship is modelled symmetric. Principle particulars of the intact ship $[21,22]$ is given in Table 1 and the tank dimensions are listed in Table 2.

The principle properties of ship under damaged condition is given in Table 3 . The worst damage location is $\pm 10 \% \mathrm{~L}_{\mathrm{pp}}$ from mid-ship. Permissible side damage as per SOLAS regulation for Ro-Ro ship is $10.9 \times 5.2 \times 6.7 \mathrm{~m}$, and for bottom damage is 11.5 $\mathrm{x} 13.1 \mathrm{x} 14.16 \mathrm{~m}$. Rectangular damage section was considered with a damage extend of $11.5 \times 13.1 \times 4.16$ $\mathrm{m}$ in damage cases D1, D3 and $8.9 \times 15 \times 4.39 \mathrm{~m}$ for damage case D2, respectively (Fig 3). The free surface correction corresponding to each damage location was calculated,and the shift in CG was estimated before the start of the simulation.

\begin{tabular}{|c|c|}
\hline PARAMETERS & PROTOTYPE \\
\hline Displacement (kN) & 164800 \\
\hline Volume displaced, $\Delta\left(\mathrm{m}^{3}\right)$ & 16391 \\
\hline Draft at $\mathrm{AP}, \mathrm{d}_{\mathrm{s}}(\mathrm{m})$ & 6.5 \\
\hline Block coefficient, $\mathrm{C}_{\mathrm{B}}$ & 0.561 \\
\hline Prismatic coefficient, $\mathrm{C}_{\mathrm{P}}$ & 0.604 \\
\hline Length overall, $\mathrm{L}_{\mathrm{oa}}(\mathrm{m})$ & 187 \\
\hline Length b/w perpendiculars, $\mathrm{L}_{\mathrm{pp}}(\mathrm{m})$ & 173 \\
\hline Breadth, B (m) & 26 \\
\hline Mid-ship section coeffcient, $\mathrm{C}_{\mathrm{M}}$ & 0.929 \\
\hline Roll radius of gyration, $\mathrm{K}_{\mathrm{xx}}(\mathrm{m})$ & - \\
\hline Pitch radius of gyration, $\mathrm{K}_{\mathrm{yy}}(\mathrm{m})$ & 45.22 \\
\hline Distance b/w top deck and keel (m) & 15.7 \\
\hline Water plane coeffcient, $\mathrm{C}_{\mathrm{WP}}$ & 0.794 \\
\hline Height from metacenter to keel, KM (m) & 14.08 \\
\hline Height from $\mathrm{G}$ to keel, $\mathrm{KG}(\mathrm{m})$ & 11.04 \\
\hline Metacentric height, GM (m) & 3.04 \\
\hline
\end{tabular}

Table 1. Properties of Ship model

Table 2. Tank dimensions

\begin{tabular}{l|c|c|c|c}
\hline Parameters/ Unit & $\mathrm{C}$ & $\mathrm{R}$ & $\mathrm{S}$ & $\mathrm{P}$ \\
\hline Length $(l), \mathrm{m}$ & 17.5 & 16.875 & - & 16.87 \\
\hline Breadth $(b), \mathrm{m}$ & - & 12.5 & - & 12.75 \\
\hline Height $(h), \mathrm{m}$ & - & 10.25 & - & 10.50 \\
\hline Upper Chamfer $\left(h_{u}\right), \mathrm{m}$ & - & - & - & 3.125 \\
\hline Lower Chamfer $\left(h_{\mathrm{l}}\right), \mathrm{m}$ & - & - & - & 1.87 \\
\hline Diameter $(D), \mathrm{m}$ & 12.5 & - & 8.02 & - \\
\hline \multicolumn{2}{c|}{$\mathrm{C}-$ Cylindrical R-Rectagular S-Spherical P-Prismatic }
\end{tabular}

Table 3. Particulars of ship under Damaged condition

\begin{tabular}{lcccc}
\hline Parameters & Unit & D1 & D2 & D3 \\
\hline Displacement & $\mathrm{N}$ & 169545 & 174175 & 210309 \\
Volume (displaced) & $\mathrm{m}^{3}$ & 16964 & 17686 & 20918 \\
Draft at A.P. & $\mathrm{m}$ & 7.589 & 7.681 & 9.04 \\
Metacentric height & $\mathrm{m}$ & 1.210 & 1.746 & 1.107 \\
Flood water weight & $\mathrm{N}$ & 4745 & 9375 & 45509 \\
\hline
\end{tabular}



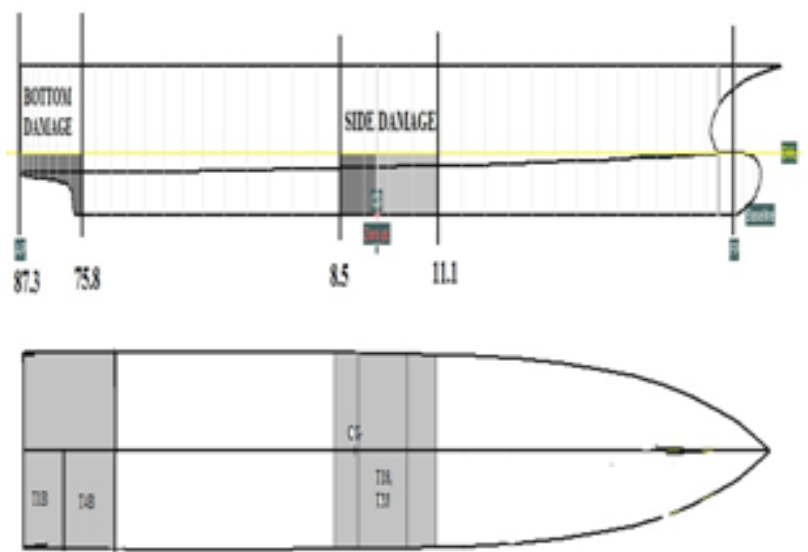

Fig. 3: Region flooded by bottom and side damage

Longitudinal bulkheads were not considered, hence damage extent throughout the width of ship. Nondamaged compartments were assumed to be watertight with a permeability 95 to $97 \%$. Sea state was split into a finite number of regular waves with a wave height of $4 \mathrm{~m}$, and the corresponding response were obtained for damaged ship corresponding to damage location shown in Fig.3. Numerical analysis was performed using FLOW3D to find the influence of flood-water sloshing on damaged ship motion and stability. The meshing of size $0.6 \times 0.5 \mathrm{~m}$ was generated. The outer mesh for wave tank had 2,408,000 mesh elements, and the inner mesh for the damaged ship had 21,060 elements. The discretization helps to capture the sloshing phenomenon on flooded compartment and the flood water ingress and egress at damage locations. The domain size for wave model is made twice that of the ship length and the ship is provided with meshing that fits its size to capture the internal sloshing dynamics, both in intact and damaged condition. The ship was subjected to wave frequency ranging between $0.024 \mathrm{~m}$ to $0.044 \mathrm{~m}$ and wave frequencies ranging between 0 to $2 \mathrm{rad} / \mathrm{s}$.

\section{Stability Characteristics of Intact Ship with Tanks}

Sloshing response study on closed compartment with liquid-filled at different levels were considered. The ship model (Table 1) was pre-processed in a geometric design modeler and the mass of the intact ship was provided with a point mass for the geometry and the amount of displaced water is found. The mesh size was adopted after the convergence analysis and the numerical analysis on beam sea was conducted.The type of mesh used was rectangular on a domain size of $370 \times 104 \times 104 \mathrm{~m}$ for wave generation and an internal mesh was provided for ship to capture the sloshing inside tanks. The intact ship with tank was considered and simulation was performed. The simulation was run for $60 \mathrm{~s}$ and the time history plot of $G M$ variation at the center of gravity of ship is plotted. Effect of sloshing in changing GM can be seen as multiple peaks occur on the GM spectrum ( Fig 4). The simulation provides motion, GM variation and pressure acting on tank walls. Fluctuation in GM at two frequencies is observed in the presence of water inside compartments which signifies the influence of sloshing on stability variation of ship.

The first peak is that of ship, and second describes the effect of sloshing and gives slosh frequency. At $75 \%$ and $50 \%$ fill, maximum GM variation was found in ship with rectangular compartment. At 25\% fill ship with cylindrical compartment shows maximum GM variation.

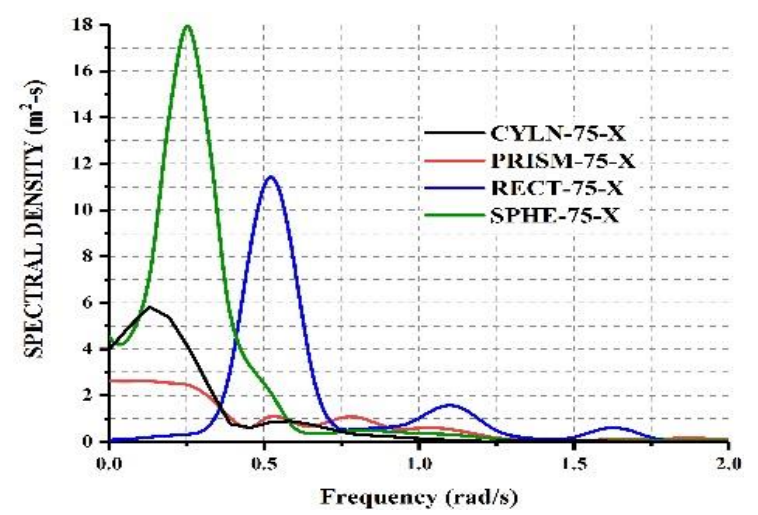

(a)

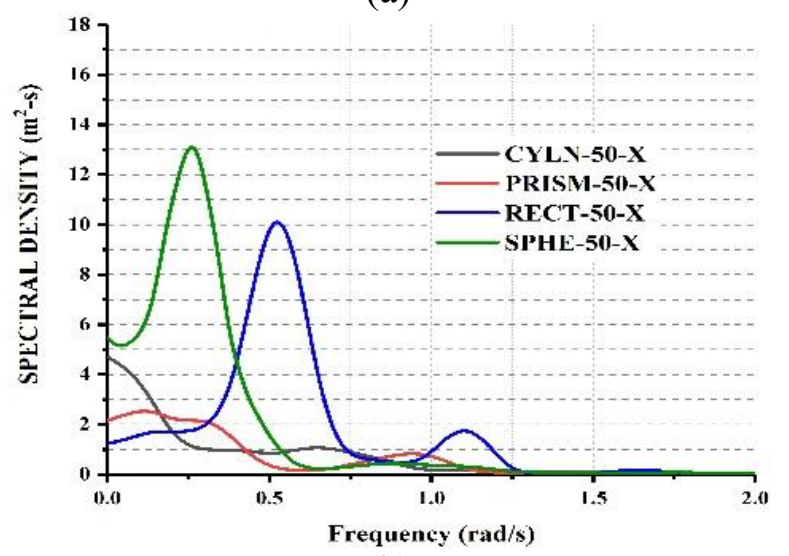

(b) 


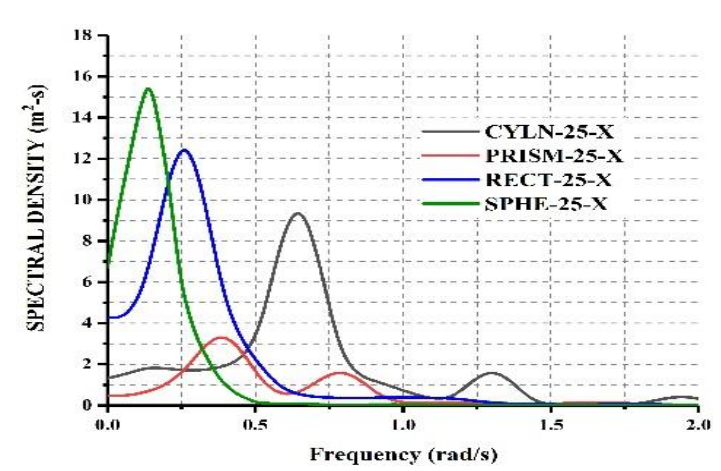

(c)

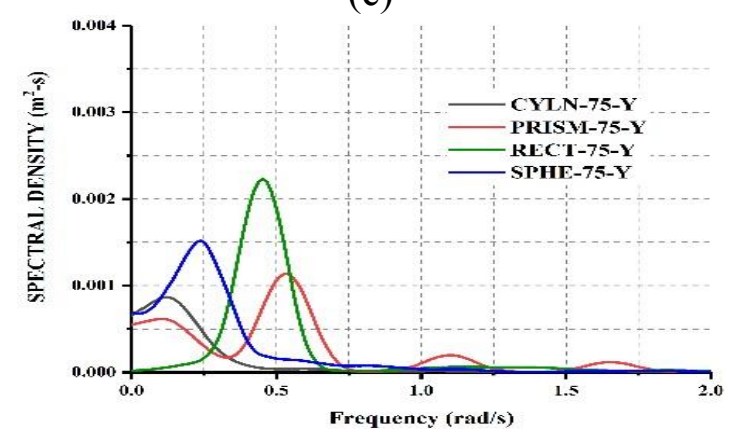

(d)

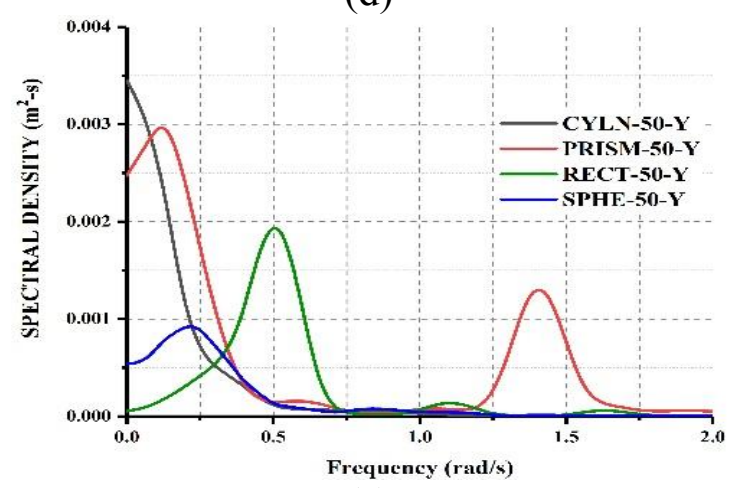

(e)

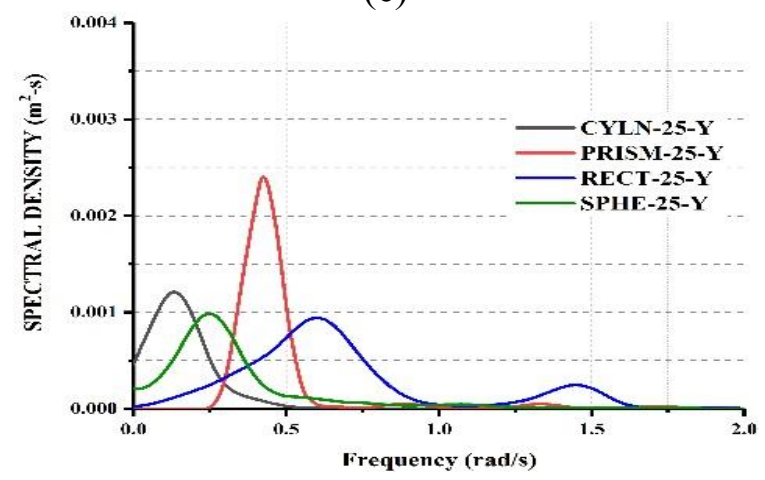

(f)

Fig. 4: GM spectrum of ship in beam sea (a) Pitch-75\% fill (b) Pitch-50\% fill (c) Pitch-25\% fill (d) Roll-75\% fill (e) Roll-50\% fill (f) Roll$25 \%$ fill
Ship with prismatic compartments shows lesser stability variations in beam sea. On head sea condition the GM spectral density variation was less, hence influence of sloshing on overall ship behaviour was insignificant (Figure 4).

It was found that sloshing in closed compartments can alter stability of ship in beam sea. Ship with open damaged compartments should be further investigated to get damaged ship response and stability.

The numerical method adopted in the present study serves as a base to the damage stability assessment of the ship with sloshing and will be insightful to researchers working in this field. Based on this study, the damage motion and stability analysis was conducted further by considering flooding water inside the ship compartments to find the sloshing effects. This study demonstrate that the shape of compartment has high influence of ship stability as sloshing behaviour of each type of tank is different.

\section{Numerical Analysis of Damaged Ship}

The response of the ship varies with the location of the damage. The motion response and stability plots or three damaged as found. The floodwater inside the chamber is assumed to be having a flat free surface initially for simulation.

The current model is assumed to be devoid of any obstacles inside the compartments. The flood water is allowed to ingress and egress at three different sections (Table 3), namely starboard, portside, and aft end, while the rest of the sections of ship remain intact.

On damage, the ship was found to undergo an initial roll angle and when the wave was generated, the flood-water sloshing moment added to the roll motion of ship and induced instability. Worst damage cases for ship under consideration is found out using probabilistic damage stability analysis in MAXSURF and named as D1, D2, and D3 (Fig 3).

Damaged compartment crossed two bulkheads; hence both compartments were considered flooded at same flood height. The ship shows asymmetric listing to the damaged side and the time at which maximum variation occurs was recorded. 


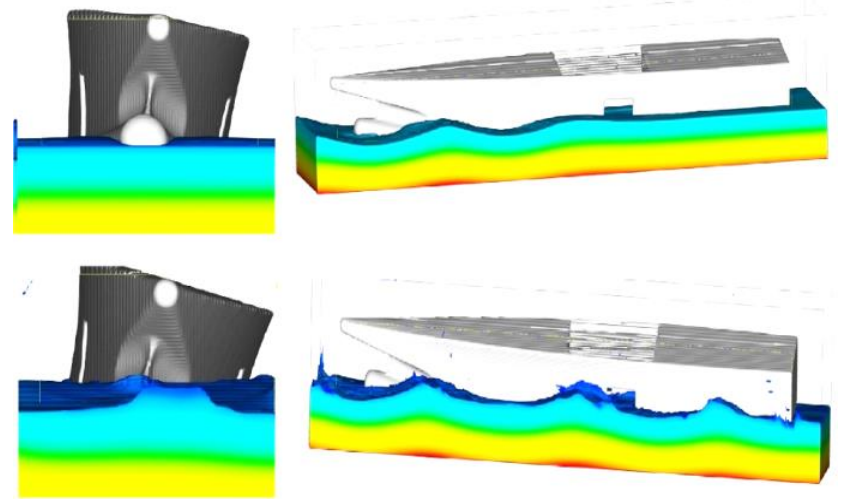

Fig. 5: Flooding of the damaged ship

Flooding of the adjacent compartment is critical than two non-compartment damage situated at a distance from each other. Compartment away from mid-ship cause extensive trim and are more dangerous than damage near mid-ship which causes less trim. When the ship's draft decreases, the stability also decreases. Lost buoyancy method assumes that flooded compartments are not part of ship after damage, while in added weight method, flood water is a part of ship weight, and free surface effect plays a vital role on the same. The waterplane area, draft, heel, trim, and buoyancy changes. On damage, the ship was found to undergo an initial roll angle and when the wave was generated, the flood-water sloshing moment added to the roll motion of ship and induced instability. The ship then reached a steady state condition and was found to be surviving in on the applied wave condition, while a change in free board was observed (Fig 6,7). The change in freeboard was varying $\left(\mathrm{FB}_{1}, \mathrm{FB}_{2}, \mathrm{FB}_{3}, \mathrm{FB}_{4}\right)$ due to flood water ingress and egress through the damage opening. The ship initially has maximum free board $\mathrm{FB}_{1}$ and as water ingress it reduces to $\mathrm{FB}_{2}$. The ship then lists towards the damaged side creating the least free board $\mathrm{FB}_{3}$. After reaching steady state the freeboard $\mathrm{FB}_{4}$ keeps varying based on the wave acting near the damaged section. As freeboard decreases, metacentric height GM decreases, hence stability decreases. It can be seen that free surface of the fluid is irregular and transient ingress of water through damage causes maximum variation of draft is from 6.5 to $9.04 \mathrm{~m}$.

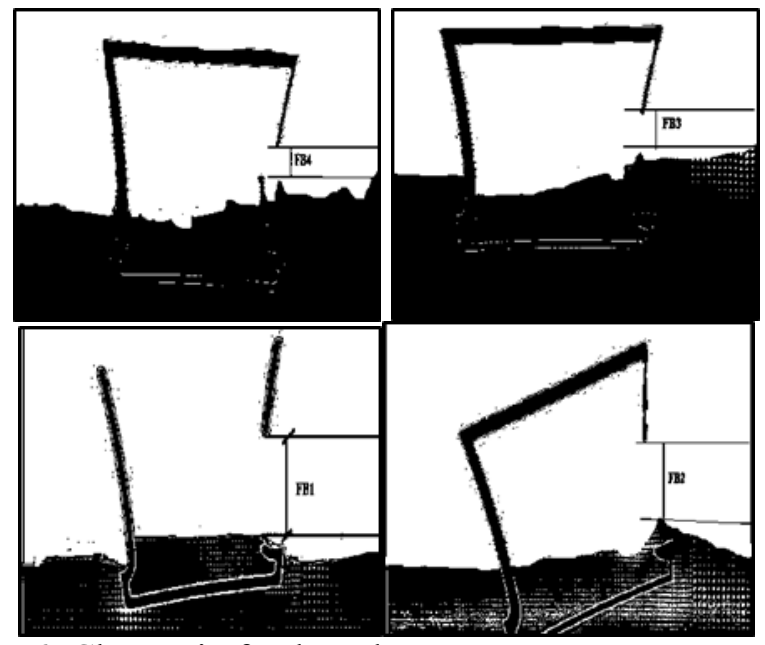

Fig. 6: Change in freeboard

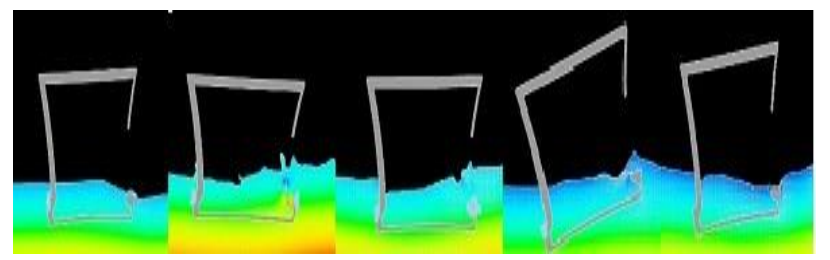

Fig. 7: Behavior of floodwater on ship with damage starboard side -Side Damage (D2)

The motion and stability of ship depend on the amount of flood-water. Internal compartment arrangements were not taken into consideration. Focus was laid on the motion and stability behaviour of ship when the location of damage opening changes. The roll in head sea and pitch in beam sea was insignificant (Figure 8-a, e).

Figure 8-b shows pitch response in head sea, where no sloshing peak was found. It is found that heave RAO is greatly influence by sloshing both in head and beam-sea at a frequency of 0.9 and $1.6 \mathrm{rad} / \mathrm{s}$ respectively (Figure $8-\mathrm{c}, \mathrm{f}$ ).

In head sea, heave RAO of ship with bottom damage $\left(\mathrm{TD}_{3}\right)$ was affected by sloshing, while in beam-sea ship with side damage $\left(D_{2}\right)$ shows sloshing peak. In the case of $\mathrm{D}_{3}$, the ship with bottom damage has maximum roll RAO of $8.2 \%$ and heave response of $1.6 \mathrm{~m} / \mathrm{m}$ (Figure 8-f). Flood-water induced pitch, roll and heave motion on ship was significant enough to generate sloshing inside compartment. 


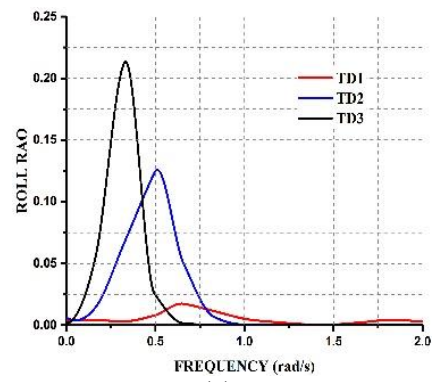

(a)

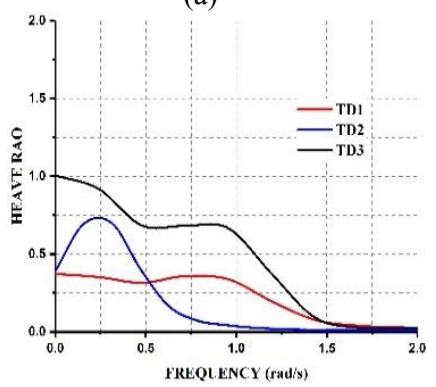

(c)

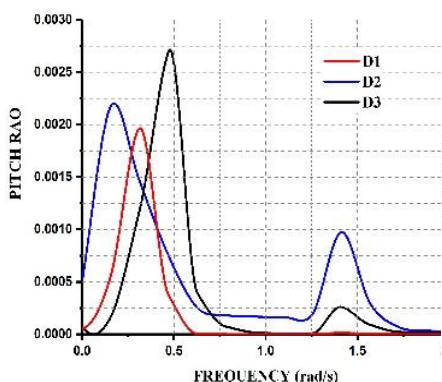

(e)

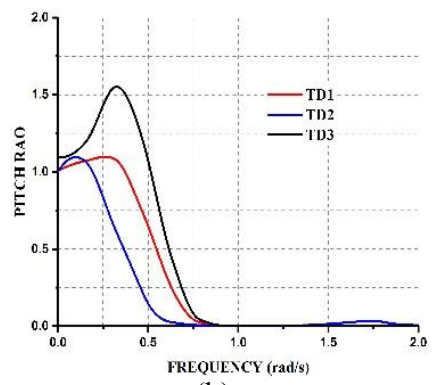

(b)

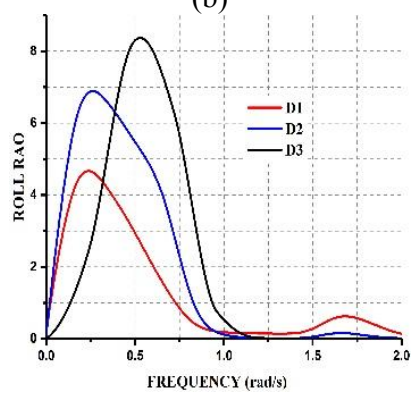

(d)

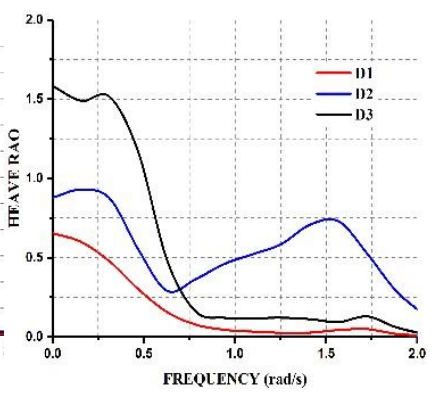

(f)
Fig. 8: Damaged ship motion response (a) head-roll; (b) head-pitch (c) head-heave (d) beam-roll (e) beampitch (f) beam-heave

The peak response frequency of damaged ship fluctuates between $0.2-0.6 \mathrm{rad} / \mathrm{s}$. The peak value of roll RAO of damaged ship with bottom damage is increased by $15.8 \%$ when compared to that of intact ship. The sloshing peak on roll RAO of ship with side damaged compartment showed a maximum of $35 \%$ decrease when compared to intact ship with sloshing. Hence, flood water sloshing can also dampen the ship motion response.

\section{Stability Characteristics of Damaged Ship}

The flood water inside compartment is trapped, and sloshing inside the compartment adds to free surface effect and causes instability. From numerical analysis, the dynamic GM variation corresponding to wave frequency ranging to $2 \mathrm{rad} / \mathrm{s}$ was recorded. The spectral analysis of these set of recorded values of dynamics GM was performed to develop Metacentric height spectrum (GM) spectrum corresponding to beam and head sea state (Figure 9). The GM spectral densities were obtained for damage ship at head sea which is represented by $\mathrm{td} 1, \mathrm{td} 2, \mathrm{td} 3$ and $\mathrm{d} 1, \mathrm{~d} 2, \mathrm{~d} 3$ in beam sea. GM spectrum gives the maximum variation of GM as a function of frequency, hence helpful to identify critical frequencies and to predict stability of ship.

The GM spectral densities of damaged ship was higher in roll response at beam sea and pitch response in head sea, and sloshing influence was less when compared to intact ship. Maximum stability variation occurs during roll motion of ship at a frequency of $0.5 \mathrm{rad} / \mathrm{s}$ in case of side damage (Figure 9). A second peak in roll response was observed at $1.5 \mathrm{rad} / \mathrm{s}$, and the influence of sloshing was significantly low.The maximum stability variation during pitch response was that of rear end bottom damage. The overall uncertainty limit of pitch response at head sea condition was obtained as \pm 15 $\%$ and that of heave RAO in beam sea was $\pm 15 \%$. The roll RAO in beam sea fall outside the $95 \%$ confidence interval.

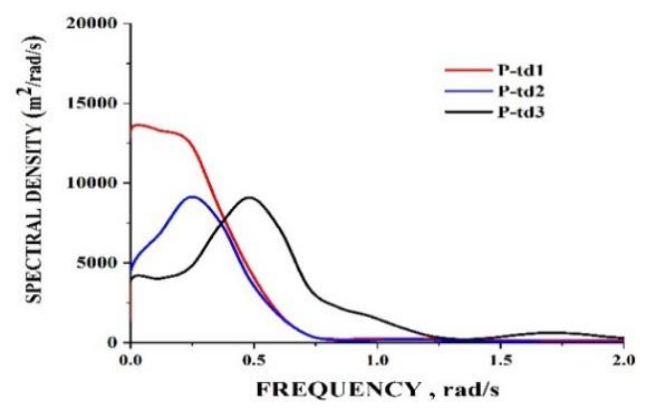

(a)

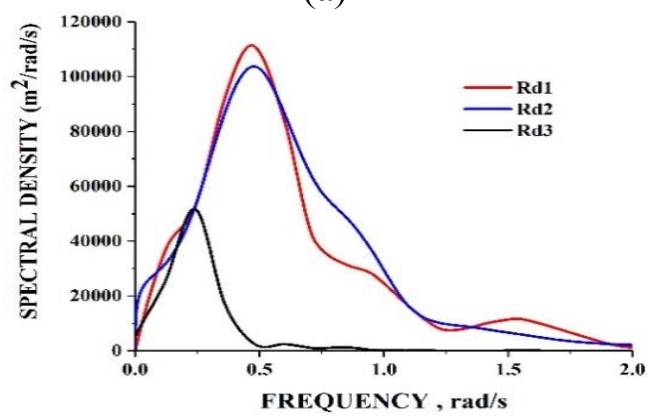

(b)

Fig. 9: Metacentric height spectrum (a) head-pitch (b) beam-roll 
The GM stability chart is as shown in Figure 10. It shows the ship GM as $3.04 \mathrm{~m}$ and the variation of $\mathrm{GM}$ at different frequencies. This helps to predict the range at which the GM of the damaged ship varies during roll and pitch in beam and head sea respectively for the given set of waves condition in this present study. The maximum variation of GM for the ship occur upto $8 \mathrm{~m}$ and the ship remains safe when the GM variation is between $1.107 \mathrm{~m}$ and 3.04 $\mathrm{m}$ (Figure 10). The corresponding frequecny of roll and pitch motion does not affect the overall stability of ship. It is reccomended by SOLAS2009 regulations that the $\mathrm{GM}_{\min }$ of $2.2 \mathrm{~m}$ should be maintained under damaged conditions. It was found that ship with rear-end bottom damages caused critical instability when compared to ship with side damage.

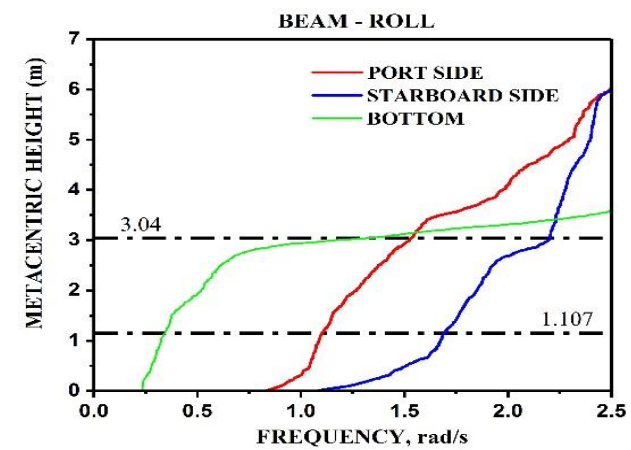

(a)

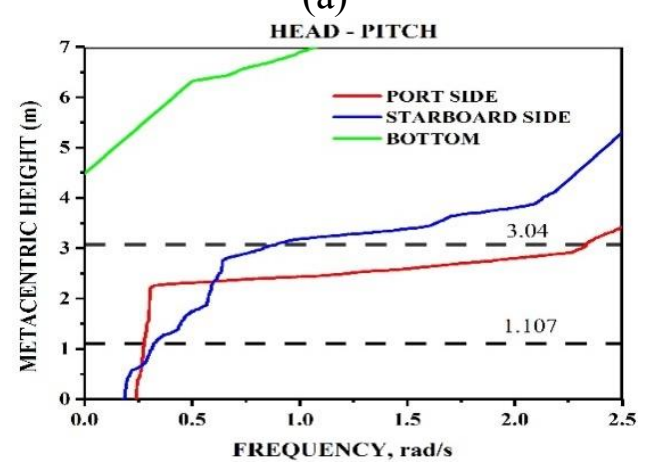

(b)

Fig 10: Dynamic GM spectrum for Ro-Ro ship in Head and Beam Sea

\section{Conclusion}

Most of the researches excludes the sloshing influence on damage stability assessment. A coupled method to include the sloshing influence on damage stability was developed. The CFD analysis was performed on ship with the critical damage location and it was found that the effect of sloshing on overall motion of damaged ship was less when compared to intact ship with fill level inside compartments. The GM spectral analysis was performed and the stability charts were developed to define the frequency at which damaged ship becomes unstable but survives at a given sea state. Numerical method adopted helps us to reach the following conclusions:

- The motion response of ship is affected by flood water sloshing. In intact condition, the effect of sloshing is higher, i.e., in closed compartments. Metacentric height varies with flooding in different tank locations. Ship with bottom damage $\left(\mathrm{D}_{3}\right)$ in beam-sea has peak roll RAO of $8.2 \% \mathrm{~m}$ and showed second peak at $1.75 \mathrm{rad} / \mathrm{s}$. The peak response frequency of damaged ship was found to fluctuate between $0.2-0.6 \mathrm{rad} / \mathrm{s}$.

- Effect of floodwater ingress and outflow through damage section was captured. Sloshing effects are higher in initial stages of flooding. Sloshing is found to induce roll behaviour in the beam sea and shows multiple frequencies during damaged condition. The sloshing peak on roll RAO of ship with damaged compartment opened to sea showed a maximum of $35 \%$ decrease when compared to intact ship. Hence, sloshing can also dampen flooded ship motion response

- The sloshing was found to be lesser in damaged ship but elevated for intact ship with fill inside compartments.The GM spectral peak was observed maximum at $0.25 \mathrm{rad} / \mathrm{s}$ in head sea and $0.5 \mathrm{rad} / \mathrm{s}$ in beam-sea and a second peak was observed at $1.5 \mathrm{rad} / \mathrm{s}$.Dynamic GM stability curve gives the GM variation for most critical conditions of Ro-Ro ship. The allowable GMmin has a value lying in the region above $1.107 \mathrm{~m}$ and below $3.04 \mathrm{~m}$ is safe.

\section{Acknowledgement:}

The author acknowledge the support provided by National institute of technology, Calicut.

\section{References:}

[1] Acanfora, M., and De Luca, F. (2016). An experimental investigation into the influence of the damage openings on ship response. Applied Ocean

Research, 
[2] Bird, H., and Browne, R. P. 1973: Damage stability model experiments, RINA Transactions, pp. 69-91.

[3] Boulougouris, E., Winnie, S., and Papanikolaou, A. (2015). Advanced damage stability assessment for surface combatants. OceanEngineering.http://doi.org/10.1016/j.oce aneng.2016.02.040

[4] De Kat J (2000) Dynamics of a ship with partially flooded compartment. In: De Kat JO, Spyrou K, Umeda N (eds) Contemporary ideas on ship stability, Elsevier, Oxford, pp 249-263

[5] Dunwoody, A. B., "Roll of a Ship in Astern Seas--Response to GM Fluctuations," Journal Of Ship Research, accepted for publication.

[6] Gao Z, Gao Q, Vassalos D.(2013) Numerical study of damaged ship flooding in beam seas. Ocean Eng 2013; 61:77-87.

[7] Hashimoto H, Kawamura K, Sueyoshi M. Numerical simulation method for damaged ships under flooding condition. In: Proceedings of the 32nd international conference on ocean, offshore and arctic engineering.

[8] Huang, Y.-S., Wang, J.-J., and Wang, S.-S. (2012). Effects of floodwater on the roll motion response of broken ships. Tianjin Daxue Xuebao (Ziran Kexue Yu Gongcheng Jishu Ban)/Journal of Tianjin University Science and Technology

[9] IMO SLF49/4/2 (2006). "Passenger ship safety." Work plan of assessment of time-toflood prediction, submitted by International Towing Tank Conference (ITTC), 5 May 2006

[10] IMO. Time-to-flood simulations for a large passenger ship - initial study. SLF46/INF.3; 2003.

[11] ITTC. Recommended procedures and guidelines, seakeeping experiments. In: Proceedings of the 26th international towing tank conference. 2011.

[12] Kambisseri, R., Hamano, T., and Ikeda, Y. (1997). Effect of water inside a ship on its damage stability. In Proceedings of the International Offshore and Polar Engineering Conference (Vol. 3).

[13] Khaddaj-Mallat, C., Alessandrini, B., Rousset, J.-M., and Ferrant, P. (2012). An experimental study on the flooding of a damaged passenger ship. Ships and Offshore Structures, 7(1). http://doi.org/10.1080/17445302.2010.532604
[14] Korkut, Emin, Mehmet Atlar, and Atilla Incecik. "An experimental study of motion behavior with an intact and damaged Ro-Ro OceanEngineering.http://doi.org/10.1016/j.oce aneng.2005.02.040

[15] Manderbacka, T., and Ruponen, P. (2016). The impact of the inflow momentum on the transient roll response of a damaged ship. OceanEngineering,120.http://doi.org/10.1016/j .oceaneng.2016.02.012.

[16] Mironiuk, W. (2013). Analysis of compartments flooding time and metacentric height after hull damage.

[17] Nishimoto, K, Torres, F., Alho, A., Sales-Jr, J., Sphaier , S.,., 2008, Experimental and Numerical Analysis of the Behavior of a Monocolumn with a Moonpool, OMAE 2008 Estoril, Portugal, 57657: 291-300

[18] Palazzi, L, and De Kat, J (2002). "Model Experiments and Simulations of a Damaged Ship with Air-Flow Taken into Account," Proc 6th Int Ship Stability Workshop, Webb Institute, New York, U.S.A. October.

[19] Pantazopoulos MS (1988) Three-dimensional sloshing of water on deck. Mar Techno 25(4):253-261

[20] Poonam Mohan, A.P. Shashikala, (2018)"Comparative Study on Sloshing Behaviour of Different Forms of LNG Tanks," International Conference on Computational and Experimental Marine Hydrodynamics, MARHY 2018,26-27 November 2018, Chennai, India, ISBN: 978-93-80689-30-2, Pg:124-131,

[21] Poonam Mohan, A. P. Shashikala (2019). "An investigation into the motion and stability behavior of a Ro-Ro Ship" Ocean Systems engineering.DOI:https://doi.org/10.12989/ose. 2019.9.2.157.

[22] Resolution, I. M. O. (1996). Agreement Concerning Specific Stability Requirements for Ro-Ro Passenger Ships Undertaking Regular Scheduled International Voyages Between or To or From Designated Ports in North West Europe and the Baltic Sea. IMO: London, UK.

[23] RRoss, C. T. F., Mourtos, I., and Papanikolaou, G. (2003). Effect of longitudinal bulkheads on damage stability of model $\mathrm{RO} / \mathrm{RO}$ ferries. Marine Technology, 40(1). 
[24] Santos, T. A., and Soares, C. G. (2009). Monte Carlo simulation of damaged ship survivability. Proceedings of the Institution of Mechanical Engineers Part M: Journal of Engineering for the Maritime Environment, 219(1).

[25] T.A.Satos, I.E., Winkle, C.Guedes Soares,(2003) "Time-domain modeling of the transient asymmetric flooding of Ro-Ro Ship" Ocean Engineering 29(2002) 667-688.

[26] Vassalos, D. (2014). Damage Stability and Survivability - 'sailing' passenger ship safety problems. Ship and Offshore Structures, 9(3), 237-256

[27] Vassalos, D., Turan, O., and Pawlowski, M. (1997). Dynamic stability assessment of damaged passenger/ro-ro ships and proposal of rational survival criteria. Marine Technology, 34(4).

\section{Conflict of Interest Statement}

The author(s) declare no potential conflicts of interest concerning the research, authorship, or publication of this article.

\section{Creative Commons Attribution License 4.0} (Attribution 4.0 International, CC BY 4.0)

This article is published under the terms of the Creative Commons Attribution License 4.0

https://creativecommons.org/licenses/by/4.0/deed.en_ US 